IZA DP No. 4682

Are Hispanic Immigrant Families Reviving the Economies of America's Small Towns?

Dennis Coates

T. H. Gindling

January 2010 


\title{
Are Hispanic Immigrant Families Reviving the Economies of America's Small Towns?
}

\author{
Dennis Coates \\ University of Maryland Baltimore County \\ T. H. Gindling \\ University of Maryland Baltimore County \\ and IZA
}

Discussion Paper No. 4682

January 2010

IZA

P.O. Box 7240

53072 Bonn

Germany

Phone: +49-228-3894-0

Fax: +49-228-3894-180

E-mail: iza@iza.org

\begin{abstract}
Any opinions expressed here are those of the author(s) and not those of IZA. Research published in this series may include views on policy, but the institute itself takes no institutional policy positions.

The Institute for the Study of Labor (IZA) in Bonn is a local and virtual international research center and a place of communication between science, politics and business. IZA is an independent nonprofit organization supported by Deutsche Post Foundation. The center is associated with the University of Bonn and offers a stimulating research environment through its international network, workshops and conferences, data service, project support, research visits and doctoral program. IZA engages in (i) original and internationally competitive research in all fields of labor economics, (ii) development of policy concepts, and (iii) dissemination of research results and concepts to the interested public.
\end{abstract}

IZA Discussion Papers often represent preliminary work and are circulated to encourage discussion. Citation of such a paper should account for its provisional character. A revised version may be available directly from the author. 
IZA Discussion Paper No. 4682

January 2010

\section{ABSTRACT}

\section{Are Hispanic Immigrant Families Reviving the Economies of America's Small Towns?*}

In the 1990s, rural areas and small towns in the United States, which had been losing population, became the destinations for an increasing number of Hispanic immigrants and their families, slowing and in some cases reversing population declines. In this paper, we examine whether faster growth in the Hispanic population is linked to faster growth in income per capita in rural areas and small towns. Our results indicate strong support for the hypothesis that Hispanic population growth has fueled increased economic growth in those small, rural communities whose populations had been in decline during the 1970s and 1980s.

JEL Classification: R11, R23, O4

Keywords: regional economic growth, Hispanics, migration

Corresponding author:

T. H. Gindling

Department of Economics

University of Maryland Baltimore County

Baltimore, Maryland 21250

USA

E-mail: gindling@umbc.edu

\footnotetext{
* We would like to thank Matthias Cinyabuguma and William Lord for helpful comments. We received financial support from a UMBC CHASS/MIPAR Faculty Fellowship.
} 


\section{Are Hispanic Immigrant Families Reviving the Economies of America's Small Towns?}

Historically, young Americans have moved out of rural areas and small towns, leaving behind smaller and older populations. Consistent with this trend, in the 1970s and 1980s population shrank in non-metropolitan areas across the Great Plains in the Midwest, Appalachia in the East, and parts of the Old South, even as the population grew on the East and West Coasts and in the Sun Belt. In the 1990s, Hispanic immigrants and their families began to look beyond traditional immigrant destinations towards these small towns and rural areas, slowing and in some cases reversing population declines in non-metropolitan areas in the United States (Johnson and Lichter, 2008; and Zuniga and Hernandez-Leon, 2005). As a recent front page article in USA Today hypothesized: "for declining counties, many in the Great Plains, the growth in young Hispanics may be the only way out of a population spiral" (El Nasser, 2008, p.1)

Johnson and Lichter (2008) show that the growth in Hispanic populations in nonmetropolitan areas is being driven as much by births to immigrant families as by immigrants themselves. Indeed, they conclude that "Hispanic population growth is self-sustaining, even if immigration were to be seriously curtailed through new restrictive legislation" (p. 342). Growth in Hispanic populations is, therefore, not only leading to population growth but also to changes in the age structure of the population in non-metropolitan areas-making it younger. This also suggests that studies of the impact of Hispanic immigration on local economies in nonmetropolitan areas should focus not on the impact of the immigrants alone, but on the total growth in the Hispanic population (including the U.S.-born children of Hispanic immigrants). New Faces in New Places: The Changing Geography of American Immigration (Zuniga and Hernandez-Leon, 2005) documents these and other changes and points out that many of these new destinations may lack the fiscal and social resources to adequately assist the newcomers as they are integrated into the community. In other words, it is not clear whether the growth of the Hispanic population in non-metropolitan and previously shrinking areas is, on balance, good or bad for small-town America.

Definitions of what is good or bad for small town America are obviously value-laden and contentious. In this paper, we focus on the simple issue of whether faster growth in the Hispanic population is linked to faster growth in income per capita in rural areas and small towns. While there is a large literature on the impact of immigration on wages, taxes, government spending and housing prices in metropolitan areas in the United States (for a review of the literature, see 
Card, 2007), we know of no published research that examines the impact of immigrationon the health of local economies in non-metropolitan and previously depressed areas, and this is especially true with respect to the influence of the growing Hispanic population on these areas. It is important to acknowledge that our analysis is not strictly of the impact of immigration as we analyze all population change, from immigration and from natural population growth. Moreover, motivated by the USA Today article and the academic research cited above, we divide population change between that arising from Hispanics and non-Hispanics. The analysis is unique due to our focus on one ethnic (immigrant) group, but the growth of this group is the principal component in the population growth in a large number of non-metropolitan and previously depressed areas.

Our results indicate strong support for the hypothesis that Hispanic population growth has fueled increased growth in per capita income in those small, rural communities whose populations had been in decline during the 1970s and 1980s. More specifically, we find that Hispanic population growth is positively linked to growth in per capita income in nonmetropolitan counties but not in counties in small or large metropolitan areas. Further, we find that Hispanic population growth is positively linked to faster income per capita growth in communities that had lost population in the 1970s and 1980s, but generally associated with slower growth in communities whose population was growing during the ' 70 and ' 80 s. Finally, we find the influx of Hispanic immigrant families had a positive effect on growth in income per capita in both non-metropolitan areas whose populations had declined and non-metropolitan areas whose populations had been rising, but the effect is substantially larger for the former than for the latter. For example, using our preferred instrumental variable estimates, a 10\% increase in the Hispanic population in non-metropolitan area counties leads to a $0.62 \%$ increase in the rate of growth of per capita income (while an increase in the non-Hispanic population in these same counties leads to a statistically significant reduction in per capita income). When we divide the sample between counties that had previously been losing population and those that had previously been gaining population, we find that a $10 \%$ increase in the Hispanic population leads to a $1.2 \%$ increase in the rate of growth of per capita income in non-metropolitan counties where population had been declining in the 1970s and 1980s, but only a $0.37 \%$ increase in those nonmetropolitan counties where population had been growing in the 1970s and 1980s. 
The remainder of this paper contains seven sections. In the first section, we discuss the literature relating immigration to regional economic growth. The second section documents the growing trend of Hispanic immigration and natural population growth outside of traditional immigrant destinations, contrasting it with trends in non-Hispanic population changes. In the second section we also state our basic hypotheses with respect to Hispanic population growth. We explain the empirical methodology and data in the third and fourth sections. Our results are discussed in the fifth and we discuss robustness in the sixth. The seventh section summarizes the results and suggests avenues of additional research.

\section{Immigration and Economic Growth}

As noted, in our empirical analysis we analyze the impact of changes in the Hispanic and non-Hispanic population on economic growth. Changes in the Hispanic and non-Hispanic population of a county may come from immigration or natural sources, although changes in the Hispanic population in a county are closely related to changes in the total immigrant population. This is not surprising given that Hispanic immigrants were such a large proportion of total immigrants to the United States in the 1990s and 2000s. For example, using data on the Hispanic and immigrant population by county for 1990 and 2000 (the data is described later in the paper), we find that the correlation coefficient between changes in the proportion of the Hispanic population in a county and changes in the immigrant population in a county is over 0.90. Unfortunately, the publicly available data do not allow us to distinguish the Hispanic immigrant population in a county from their children. Our focus on population change rather than immigration means that our analysis and inferences must be careful to provide the appropriate caveats and qualifiers that our results are not direct tests of theories related to immigration and growth.

In this section, we review the economic literature linking immigration to growth in income. In neo-classical models of economic growth, the impact of natural population increase on growth in per capita incomes is negative while the impact of immigration on economic growth is ambiguous. The simple Solow model of economic growth in a closed economy predicts that growth in the population will reduce per capita income growth. In the short run (holding capital constant) diminishing marginal returns to labor implies that output per worker will fall as more workers are added to a fixed amount of other factors of production. In the long 
run steady state, a higher population growth rate reduces the rate of growth in the capital labor ratio, which in turn reduces the rate of growth in output per capita. However, as Barro and Salai-Martin (1995 and 2004) point out, migrants differ from the native-born population, in part because they bring with them accumulated human capital (while newly-born natives must acquire human capital locally). Immigration thus has two, counteracting, effects on per capita income growth: the higher labor supply will slow growth, while the higher human capital brought by migrants will promote growth. Barro and Sala-i-Martin (1995) show that immigration will promote growth in per capita incomes (the positive effect of higher human capital will counteract the negative effect of a higher labor supply) if the human capital of immigrants is substantially greater than the human capital of natives. They write, however, that "this condition is unlikely to be satisfied because, as already noted, immigrants tend to have less human capital than the residents of the receiving economy" (p.293). Although this may be true for traditional immigrant destinations in metropolitan areas with booming economies, we suggest that this condition is likely to be fulfilled in localities where the population and economic growth had been declining. In those localities, the younger native-born have largely moved out, leaving behind an older population with relatively little human capital (or human capital that has depreciated with time). New, young Hispanic immigrants with families may not only bring measurable human capital (such as education), but also, and perhaps more importantly, intangible and unmeasurable human capital such as motivation to succeed, an ability to innovate, and entrepreneurial talent; they may be more willing to work long and hard and at jobs natives will not take. ${ }^{1}$ In addition, because they have a longer time horizon to recoup their initial investment, younger migrants may be more willing to invest in training and physical capital than older natives (Becker, 1993). Young immigrants may also be more receptive to innovations that could disrupt the lives of older, established populations. ${ }^{2}$ This implies that immigrants into

\footnotetext{
${ }^{1}$ There is an extensive literature arguing that migrants are favorably self-selected (for example, see Borjas, 1987 and Chiswick, 1999). Borjas, Bronars and Trejo (1992) find that this favorable self-selection is greater for internal migrants within in the United States (between regions) compared to international immigrants. Chiswick and Miller (2008) show that in the United States this favorable self-selection is more pronounced among less-educated workers compared to more-educated workers. Grey and Woodrick (2005) document this positive self-selection of Hispanic immigrants in the context of an American small town, Marshalltown lowa.

${ }^{2}$ Poot (2008) argues (or hypothesizes) that because younger people are more likely to migrate, outmigration from a region generally results in population aging and is empirically associated with a loss of regional competitiveness, while youthful immigrants bring entrepreneurship and other general human capital that have growth-enhancing effects. Parente and Prescott (1999) argue that younger people are more likely to adopt growth-inducing innovations than are older generations, because older generations have specific human capital that is attached to
} 
small towns and rural areas that had been declining may indeed have substantially more (measurable and unmeasureable) human capital than the labor force already in those localities, and therefore immigration into these areas may have a positive impact on per capita incomes.

U. S. counties are not closed economies; not only is labor and human capital mobile between counties but so is physical capital (at least in the long run). Brezis and Krugman (1996) present a simple theoretical model of immigration in an open economy with mobile physical capital and the possibility of increasing returns to scale. In such an open economy, immigration will induce firms to invest and innovate, and increasing economies of scale will result in output increasing more than proportionately as immigration occurs (increasing income from capital as well as labor). Thus, in the long run, immigration results in both increases in wages and increases in per capita income. If human capital and physical capital are complements, then immigration can be expected to induce greater investment and innovation and therefore have a more positive impact on economic growth. In an open economy such as U.S. counties, immigration is therefore even more likely to have a positive impact on per capita incomes.

Complementarity between immigrant and native workers could also promote a positive causal relationship between immigration and per capita income. Ottaviano and Peri (2006) and Peri (2007) present evidence that in the U.S. more-educated native workers and less-educated immigrants are complements. If this is the case, the influx of Hispanic families may lead to an increase in demand for more-educated native labor (managers, teachers, doctors, insurance agents, lawyers, etc.). Since many of the educated youth have left small towns and rural areas and are unlikely to return, the supply for educated labor in these non-metropolitan areas is likely to be very inelastic. A less elastic supply of educated labor implies that similar increases in demand for educated workers in non-metropolitan areas is likely to lead to greater wage increases than in metropolitan areas where the supply of educated labor is likely to be more elastic. Immigrants may thus have a double benefit to the local economy, directly by supplying factors of production that are in short supply and indirectly by making educated native labor more productive.

Although there is a large empirical literature on the impact of immigration on wages, there is much less empirical literature on the impact of immigration on per capita income. As

older, established technologies. Parente and Prescott (1999) and Parente and Zhao (2006) also point out that this type of "human capital" of younger people is not measureable using traditional measures of human capital. 
Hanson (2008, p.26) writes, "So far, empirical literature has little to say about the impact of immigration on non-labor income." Since immigration can be expected to change income from capital and entrepreneurial effort as well as labor, knowledge of the impact of immigration on wages is not sufficient to determine the impact of migration on per capita income. Among the studies which directly estimate the impact of immigration on per capita income, Dolado, Goria and Ichino (1994) use a national-level panel data set of OECD countries to estimate Solow models of growth that include and exclude migration variables. Most similar to the current study are those papers which examine the impact of internal migration on economic growth in different regions of a given country, where growth is in per captia income or per capita output. Using data on U.S. states, Japanese prefectures, and regions in Germany, the U.K., Italy, France and Spain, Barro and Sala-i-Martin $(1995 ; 2004)$ report estimates of empirical growth models that both include and exclude a net migration variable. Barro and Sala-i-Martin $(1995 ; 2004)$ find that, after instrumenting for population growth with weather and population density variables, the net immigration variable has an insignificant impact on economic growth. Following the approach used in Barro and Sala-i-Martin (1995; 2004), other empirical research examining the impact of migration on regional economic growth comes to mixed conclusions. ${ }^{3}$ Positive, negative and no effects are found, sometimes even for the same country. For example, Perssons (1997) and Shioji (2001) find that net migration has a positive impact on regional economic growth in Sweden and Japan, respectively; Peeters (2008) finds that net migration has a negative impact on regional economic growth in Belgium; and Soto and Torche (2004) find that net migration has an insignificant impact on regional economic growth in Chile. Studying Turkey, Kirdar and Saracaglu (2007) find that net migration has a negative impact on regional economic growth while Gezici and Hewings (2004) find there is no significant impact of net migration on growth. Etzo (2008b) and Osterbye and Westerlund (2007) show that the impact of migrants on regional economic growth depends on the characteristics of migrants, and that outmigration may have different effects from in-migration. Etzo(2008b) finds that, on average, a net gain of migrants has a small positive impact on regional growth in Italy, but that the positive impact of net immigration occurs only if migrants are more highly skilled than natives. Etzo (2008b) further finds that the impacts of outmigration and immigration on economic growth are not symmetrical; while emigration has a negative impact, and immigration

\footnotetext{
${ }^{3}$ This literature is summarized in Ozgen, Nijkamp and Poot (2009) and Etzo (2008a).
} 
has a positive impact, on economic growth, the quantitative impact of emigration on regional growth is larger. He infers from these results that the positive impact of net migration on economic growth in Italian regions is driven by selective emigration rather than immigration. Etzo (2008b) concludes that these results reflect patterns of migration where regions with high emigration rates tend to lose high skilled workers while regions with high immigration rates tend to gain low skilled workers. Osterbye and Westerlund (2007) find that net migration has a positive impact on regional growth in Norwegian counties but a negative impact in Swedish counties.

An additional issue that arises in models which allow for migration is the extent to which migration affects the speed of convergence to long run equilibrium. An early and important question in the growth literature concerned how quickly, if ever, low income countries or regions would catch up to high income areas. While it is not our focus, our analysis estimates the convergence coefficient for counties of the United States, so we mention the results in the literature here to provide a basis of comparison to our findings. Dolado, Goria and Ichino (1994) report that adding the migration variable to their national level panel data models of growth reduces the convergence coefficient. Barro and Sala-i-Martin (1995; 2004) also find weak evidence that adding immigration to a Solow migration model raises the convergence coefficient. Barro and Sala-i-Martin (2004, p.486) write: "The evidence here is not definitive but suggests that migration plays only a minor role in the convergence story." Osterbye and Westerlund (2007) suggest a more nuanced interpretation inferring from their results that "migration between counties with different human capital endowments is more important for convergence than the mobility between similar counties" (p. 912).

The empirical literature on the impact of net population growth and immigration on growth in per capita income thus provides mixed results, even when authors examine the same or similar countries. This is not surprising, given that the theory described above indicates countervailing influences of immigration on growth. ${ }^{4}$ If the relative human capital of migrants and natives differs between regions, as we argue it might differ between regions where population had been declining and areas where population and the economies had been growing,

\footnotetext{
${ }^{4}$ Ozgen, Nijkamp and Poot (2009) note that different results may also be due to the econometric technique used to estimate the impact of immigration on regional economic growth, with studies that use panel data and instrumental variable estimates yielding smaller coefficient estimates on the migration variable in the growth regression.
} 
then it is also important to estimate the impact of immigration on economic growth separately for these areas. We know of no studies in the literature that estimate the impact of immigration on economic growth in small towns and rural areas, or for local areas that had been losing population compared to local areas that had been gaining population. As immigration to rural areas is largely from Hispanics, as indicated in the popular press and academic research cited above, our focus is on the impact of this group. We turn now to documenting this contribution of the Hispanic immigrants and their families to rural and small town population change during the 1990s and 2000s.

\section{Population Trends and Hypotheses}

We use data from the County and State Data Book on the Hispanic and non-Hispanic populations for each county in the U.S. to construct Figures 1 and 2. In Figure 1 the U.S. counties that experienced population declines in the 1970 s or 1980 s are colored white. Figure 1 shows that in the 1970s and 1980s population shrank in non-metropolitan areas across wide swaths of the Great Plains in the Midwest, Appalachia in the East, and parts of the Old South. ${ }^{5}$ Figure 2 identifies the U.S. counties that experienced increases in Hispanic populations in the 1990s and 2000s even as non-Hispanic populations continued to decline (these counties are shaded light green), compared to counties that continued to lose both Hispanic and non-Hispanic populations (white) or gain both Hispanic and non-Hispanic populations (dark green). As is clear from a comparison of Figures 1 and 2, counties which would have continued population declines were it not for an increase in the Hispanic population are often the same as those counties in the Midwest, Appalachia and the Old South where populations shrank in the 1970s and 1980s.

Table 1 reports the percentage change in total population, Hispanic, and non-Hispanic population within counties classified by metropolitan status and the change in population during the 1970 s and 1980s. ${ }^{6}$ The evidence from the table reveals that, on average, in the 1990s and

\footnotetext{
${ }^{5}$ Counties that are losing population are also likely to be counties that have depressed economies. For the 19702005 period, the correlation coefficient across counties between population growth rates and growth rates in real income is 0.83 . Between 1970 and 1990 , over $20 \%$ of the counties that lost population experienced a decline in total real income, while less than $2 \%$ of the counties with growing populations experienced negative economic growth).

${ }^{6}$ Our data provide evidence to confirm the results in the literature that those who moved out tended to be younger, so that the typical resident became older in those counties that lost population. By 1990, in those
} 
2000s population growth resumed in counties that had been shrinking in the 1970s and 1980s, despite a continuing decline in the non-Hispanic population in these counties. Population growth resumed in counties of all sizes whose populations had been shrinking in the 1970s and 1980s because the growth of the Hispanic population in those counties outweighed the loss of nonHispanics. $^{7}$

Grey and Woodrick (2005) provide context for these trends from a specific destination city, Marshalltown, Iowa. They document the rapid growth in the Hispanic population, predominantly Mexicans from the same town in Mexico, and indicate the impacts on the community. One impact is "the 2000 census would have shown further population decline if it were not for the in-migration of Mexicans" (Grey and Woodrick, 2005, p. 136). Marshalltown had been losing population, in part because natives were unwilling to take jobs in the town's largest employer, a meatpacking plant, and the existing population was getting older. Prior to the rapid growth in the immigrant population, employers in Marshalltown were unable to find qualified employees as the number of applicants per opening was less than one. In agriculture generally, there was about one applicant for every two job openings, and at the meatpacking plant there were two applicants for every three openings.

The aggregate data and the Marshalltown experience suggest a clear role for Hispanic immigrants in reversing the population declines and, possibly, the income decreases experienced by rural America. We hypothesize that the impact of Hispanic immigration and natural population growth on the economies of non-metropolitan counties is different from the impact of

counties that lost population in the 1970s and 1980s, the proportion of the population 65 years old or older was $17 \%$, compared to only $13 \%$ in counties where population had been growing. Over all years, the correlation between the proportion of a county's population that is Hispanic and the proportion 65 and older is negative ($0.10)$.

7 Our data also provide evidence that the influx of Hispanics into a county makes the population and workers younger. The correlation between the proportion of a county that is Hispanic and the proportion of the population that is young working age (18-44) is positive, while the correlation between the proportion of the county that is Hispanic and the proportion of a county's population that is 65 years or older is negative. To estimate of the causal impact of Hispanic immigration into a county on the age structure of the population of working age, we also estimated first difference regression where the dependent variable is log of the proportion of young working age population (18-44) and the independent variables include the log of the Hispanic population, the log of the nonHispanic population, and year dummy variables. Following the procedure described in section 2, to correct for potential endogeneity we also instrument the population variables with the number of heating days, cooling days, and the lagged Hispanic population. The results of these estimations indicated that an increase in the Hispanic population of a county causes a statistically significant increase in the proportion of the population between 18 and 44 years old, while an increase in the non-Hispanic population causes a statistically significant fall in the proportion of the population between 18 and 44 . 
increased Hispanic population growth on metropolitan areas, and that the impact of Hispanic population growth on the economies in depressed areas may be different from the impact of increased Hispanic population growth in areas that already have booming economies.

Non-metropolitan counties, especially those that experienced declining population in the 1970s and 1980s, may suffer from insufficient supply of capital, labor, and entrepreneurial spirit. The young Hispanic immigrant families may provide each of these to their new community as well as a willingness to tackle difficult, dangerous, or unpleasant jobs. In other words, the immigrant families supply resources in short supply which, therefore, may have a larger positive effect on a local economy than those same resources would have where they are plentiful. Consequently, in our analysis we will estimate the impact of Hispanic population growth on the local economies of counties that had been declining, separately from the impact on the local economies of counties that were already growing. We will also estimate the impact of Hispanic population growth separately for declining and growing counties in large metropolitan areas, smaller metropolitan areas and non-metropolitan areas.

\section{Methodology}

To test the hypothesis that Hispanic population growth and non-Hispanic population growth might have different impacts on economic growth in a county, we will estimate economic growth equations using county-level panel data. Following the practice in the empirical growth literature, we estimate a growth equation of the form:

$$
\begin{aligned}
& \ln \left(y_{i t}\right)-\ln \left(y_{i t-1}\right) \\
& \quad=\ln \left(y_{i t-1}\right) \sigma *+x_{i t} \beta+\ln \left(\text { hisp }_{i t}\right) \gamma_{1}+\ln \left(\text { nonhisp }_{i t}\right) \gamma_{2}+C_{i}+T_{t}+\varepsilon_{i t}
\end{aligned}
$$

or, equivalently

$$
\ln \left(y_{i t}\right)=\ln \left(y_{i t-1}\right) \sigma+x_{i t} \beta+\ln \left(\text { hisp }_{i t}\right) \gamma_{1}+\ln \left(\text { nonhisp }_{i t}\right) \gamma_{2}+C_{i}+T_{t}+\varepsilon_{i t}
$$

Where $y_{i t}$ is the log of real income per capita in county i during year $t, x_{i t}$ is a vector of human capital characteristics of the county's population, including variables reflecting educational attainment and age distribution. The $\mathrm{C}_{\mathrm{i}}$ are county fixed effects and $\mathrm{T}_{\mathrm{t}}$ are time fixed effects. Among other things, the county-specific fixed effects reflect the initial level of technology, geographic location, culture, and county-specific measurement errors. Time fixed effects reflect changes over time that are assumed to be common to all counties, such as the rate of change in 
productivity and the depreciation rate. $\sigma, \gamma_{1} \gamma_{2}$ and the vector $\beta$ are parameters to be estimated, and $\varepsilon$ captures unobserved and or unobservable influences on the economic growth.

The lagged value of the income per capita reflects the levels of technology and factors of production (such as capital) at the beginning of each period. This empirical growth equation is an operationalization of the basic Solow neoclassical growth model, augmented with human capital (details of the derivation of the empirical growth equation from the Solow growth model can be found in Hoeffler, 2002; Bond, Hoeffler and Temple, 2001; Hall and Jones, 1999; Caselli, Esquivel and Lefort, 1996; and Mankiw, Romer and Weil, 1992). In the Solow model, counties that begin with higher output per worker will grow more slowly so that, over time, the Solow model predicts convergence towards a steady state output per capita growth rate across counties. This implies that we expect the coefficient $\sigma$ to be negative (formally, $\sigma=\sigma^{*}+1=-\mathrm{e}^{-\psi t}$, where $\psi$ denotes the rate of convergence to the steady state). The model predicts that investment in human capital will have positive effects on economic growth. On the other hand, holding other factors of production constant, the Solow model predicts that growth in the labor force will have a negative effect on growth in output per worker. Thus, the Solow model predicts that the estimated coefficients on the population variables in the growth equation will be negative.

We extend the basic empirical economic growth model by allowing the impact of population growth on economic growth to differ depending on whether the population growth is in the Hispanic population (hisp $\mathrm{it}_{\mathrm{it}}$ ) or the non-Hispanic population (nonhisp $\mathrm{p}_{\mathrm{it}}$ ). We follow Hall and Jones (1999) and use the levels of the population as independent variables. Earlier we explained why we hypothesize that Hispanic population growth may have a positive impact on income per capita in non-metropolitan counties that have been experiencing declining population and economic recession. The coefficients $\gamma_{1}$ and $\gamma_{2}$ can be interpreted as change in the rate of growth in real income per capita brought about by a one percent increase in the Hispanic or nonHispanic (respectively) population. Using $\gamma_{1}$ and $\gamma_{2}$, we test the hypothesis that the impact of Hispanic population growth on economic growth differs from the impact of population growth in general. In addition, we test the hypothesis that the impact of Hispanic immigrants on the local economy differs for counties experiencing growing populations and those experiencing declining populations and the hypothesis that Hispanic immigrants have a different impact in large metropolitan counties, small metropolitan counties, and non-metropolitan counties. 
Our interest is in the causal impact of population growth on the local economy, but there is likely to be an endogenous relationship between the vitality of a local economy and population growth that may make causality difficult to determine. That is, a positive correlation between population growth and local per capita income could be due to a growing local economy attracting a larger population rather than a higher population causing a growing local economy. On the other hand, the evidence presented in the last section suggests that in the 1990s and 2000s Hispanic immigrant families were attracted to counties with declining populations and economies. In this case, the bias in the estimate of the impact of population growth on economic growth could be in the opposite direction. Failure to account for this reverse causation would produce biased and inconsistent coefficient estimates. We will address this possible reverse causation (endogeneity) issue using instrumental variables methods. We will first estimate a two-stage-least-squares (2SLS) instrumental variable (IV) model where we instrument the Hispanic and non-Hispanic population growth using historic Hispanic immigration trends and the number of heating days and cooling days (which reflect whether recent temperatures have been comfortable). These are instrumental variables used commonly in the literature on the impact of population growth and migration (see, for example, Card, 2007, Saiz, 2003 and 2007; and Barro and Sala-i-Martin, 2004).

The 2SLS-IV technique may result in biased estimates of the coefficients because the presence of a lagged dependent variable as an explanatory variable in the estimated growth equation creates a potential bias, as the lagged dependent variable will be correlated with the error term in the regression. Arellano and Bond (1991) develop a dynamic panel data model that addresses the problems of the correlation between the lagged dependent variable and the error terms (and also the potential problem of first-order autocorrelated errors). In addition, the Arellano and Bond technique provides additional instrumental variables that can be useful in addressing the endogeneity of other independent variables (such as Hispanic and non-Hispanic population growth). The Arellano and Bond "difference GMM" model estimates the regression using first differences, and uses the values of the levels of the exogenous variables lagged two or more periods as additional instruments for the potentially endogenous independent variables (in addition to the temperature variables used in the 2SLS-IV). We follow Arellano and Bond (1991) and use the simplest two period lag structure in constructing the instrumental variables (limiting the number of lags is also important because of the limited time series in the data). 
Blundell and Bond (1998) show that the difference GMM estimator developed by Arellano and Bond performs poorly when the time series are highly persistent over time. In this case, lagged levels of the variables are weak instruments for subsequent first differences. Blundell and Bond (1998) develop a "system GMM" estimator that combines the first difference equations described in the last paragraph with an additional set of equations in levels that use lagged first differences as instruments.

In this paper, we present estimates using the 2SLS-IV estimator, the difference GMM estimator, and the system GMM estimator (as well as the simple OLS fixed-effects estimator for comparison purposes). As we shall see, our results are not sensitive to the econometric technique used to estimate the growth equation.

\section{Data}

We construct a panel data set of all U.S. counties for the years 1970, 1980, 1990, 2000 and 2005. From the County and State Data Book, we collected, for each county in the U.S. for each year, data on per capita income and the Hispanic and non-Hispanic populations. Nominal per capita income is deflated using the most detailed regional Consumer Price Index available. Variables reflecting the educational attainment and age structure of the population of each county also come from the County and State Data Book and are available for 1980, 1990 and 2000 (these variables are the proportion of the population: with a high school education, with a college education, between 0 and 5 years old, between 18 and 65 years old, and older than 65). From the National Ocean and Atmospheric Administration (NOAA) we collected the number of heating degree days and cooling degree days for each county for 1980, 1990, 2000 and 2005. Heating degree days is a measure of how often the temperature falls low enough that buildings need to be heated, cooling degree days measure how often the temperature is high enough that buildings need to be air conditioned; as such they are measures of whether recent temperatures have been too hot or too cold to be comfortable outside.

We first estimate growth equations for all counties, and then estimate growth equations separately for counties that are part of a Primary Metropolitan Statistical Area (PMSA--larger cities), for counties that are part of other Metropolitan Statistical Areas (other MSAs--smaller metropolitan areas), and for counties that are not in an MSA (small towns and rural areas). Appendix table A presents summary statistics of the variables used to estimate the growth 
regressions for all counties and for non-MSAs. The full panel is of 3101 counties, with observations at five points in time over a 35 year period (1970, 1980, 1990, 2000 and 2005). The first four columns of table A present the average growth in per capita income across counties for 1970-1980, 1980-1990, 1990-2000 and 2000-2005. On average, income growth rates are highest in the 1970s and 1980s. The next set of columns in table A present summary statistics for the variables used to estimate the growth regressions. Because the regressions include values of the dependent and independent variables lagged one period, and because some of the variables needed to estimate the regression are not available in 2005 , the explanatory variables used to estimate the economic growth equation are from 1980, 1990 and $2000 .^{8}$

\section{Results}

The results of the economic growth regressions estimated using data from all counties are presented in table 2. The estimated equations perform well. In all specifications, the coefficients are almost always statistically significant and the signs of the coefficients are as expected. The coefficients on the education variables are positive and significant, and counties with a higher working age population (18-64 years old) have faster economic growth. In all specifications, the coefficient on the lagged dependent variable is negative, significant and within the range reported in the literature. We have more to say about this coefficient below.

The instrumental variables in the 2SLS-IV regressions are required to fulfill two conditions: they must be correlated with the variables that they instrument for, and they must be uncorrelated with the error term in the economic growth regression. We test whether our data fulfill the first assumption by jointly testing the statistical significance of the instrumental variables in the first-stage regressions. In both first stage regressions (where the dependent variables are the log of the Hispanic population and the log of the non-Hispanic population, respectively) the instrumental variables, as a group, are always highly statistically significant. The cold degree days and heating degree days instrumental variables are significant for both Hispanic and non-Hispanic populations in almost all first-stage regressions, no matter the sample

\footnotetext{
${ }^{8}$ The total number of observations for each variable used in the regression is 9303 (3101 counties for three years). The number of observations used in each regression is less than 9303 because we do not have data on heating degree and cooling degree days (instrumental variables) for all counties and years and because we use the log of the Hispanic population as an explanatory variable in the regressions, and therefore lose the 78 county/year combinations where the Hispanic population is reported as zero.
} 
used. In the regressions reported in table 2, in the first stage regressions the lagged Hispanic population variable is significant and negative for both the Hispanic and non-Hispanic populations. In the first stage regressions for other sub-samples of the counties, the lagged Hispanic population variable is almost always a significant and negative determinant of Hispanic population growth, but is most often an insignificant determinant of non-Hispanic population growth. The negative relationship between lagged Hispanic population and current growth in the Hispanic population is consistent with the phenomenon that Hispanics have recently been moving disproportionately to non-traditional destinations (where historically the Hispanic population is small). The Sargan/Hansen test statistics, reported at the bottom of table 2, test the null hypothesis that the instrumental variables are correlated with the error term in the economic growth regression. The p-values of the Sargan/Hansen test statistics for the 2SLS-IV estimates indicate that we can reject the hypothesis that the instrumental variables are correlated with the error term in the structural equation. Also reported at the bottom of table 2 are Hausman test statistics for the null hypothesis that the 2SLS-IV estimates are not significantly different from the simple OLS estimates with county fixed effects. We can clearly reject this hypothesis, indicating that endogeneity bias is present in the simple OLS estimates and, therefore, that the 2SLS-IV estimates are preferred.

The difference and system GMM estimates assume that the errors in the non-differenced equations are serially correlated of degree 1 . Table 2 presents the test statistic developed in Arellano and Bond (1991) to test the null hypotheses that the errors do not exhibit serial correlation. We can reject the null hypothesis, indicating that the difference and system GMM estimates are appropriate. However, the Sargan/Hansen statistics indicate that the expanded instrumental variable set used in the difference and system GMM estimates is correlated with the error term in the structural equation. This leads us to view the GMM results with some skepticism. Given doubts about the validity of the instruments used in the difference and system GMM estimates, our preferred estimates are the 2SLS-IV estimates, although our qualitative conclusions are not sensitive to the technique used to estimate the growth regressions.

The non-Hispanic population variable has a negative but insignificant coefficient in the OLS fixed effects regression. As discussed previously, the estimate of this coefficient may be biased due to reverse causation, or endogeneity, between economic growth and population growth (higher economic growth could attract a higher population). The 2SLS-IV and GMM 
estimators are an attempt to correct for this endogeneity bias, and in the 2SLS-IV estimates the coefficient on the non-Hispanic population variable becomes more negative and statistically significant. This negative and significant coefficient is consistent with the effect of population growth on economic growth predicted by the Solow model. The coefficient on the non-Hispanic population variable is also negative and significant in the difference GMM estimate, but not in the system GMM estimate.

On the other hand, the coefficient on the Hispanic population variable is positive and significant in all specifications. Further, the size of the coefficient increases when we compare the 2SLS-IV and GMM estimates to the OLS fixed-effects estimate. This implies that Hispanics are being attracted to slow growing counties, and that once we control for this type endogeniety the positive impact of Hispanic immigration on county per capita income growth is larger. In our preferred 2SLS-IV estimates, a $1 \%$ increase in the Hispanic population of a county leads to about a $0.07 \%$ increase in the growth rate of real per capita income.

The coefficient on the lagged value of log income per capita is an estimate of $\sigma\left(=-\mathrm{e}^{-\psi \mathrm{t}}\right)$ and an indication of the speed of convergence to the steady state level of income per capita. Barro and Sala-i-Martin $(1995,2003)$ show that in the Solow neoclassical model of economic growth, including the potential for migration in the theoretical model raises the convergence coefficient $(\psi)$. For our analysis, this larger convergence coefficient would mean an estimated value of $\sigma$ smaller in absolute value. Moreover, "if migration is an important source of convergence", when migration is appropriately accounted for in the regression analysis, "then the estimated convergence coefficient $(\psi)$ should become smaller" (Barro and Sala-i-Martin,1995, p. 410). This implies that we should observe the absolute value of the coefficient on the lagged value of per capita income in the growth regressions to be larger in regressions that omit the population variables, compared to regressions that include the population variables and correct for endogeneity (the latter results are presented in table 2). When we re-estimate the equations reported in table 2 , but omit the population variables, the absolute value of the coefficient on the lagged dependent variable is always larger than the absolute value of the coefficient on the lagged dependent variable in the specifications reported in table 2. In other words, our data and models conform to the Barro and Sala-i-Martin theoretical analysis. ${ }^{9}$

\footnotetext{
${ }^{9}$ This is also true when we consider only the sub-sample of non-metropolitan counties (whether growing or declining in population). When we re-estimate the economic growth regressions for these sub-samples of
} 
Our results are also similar to their empirical findings which provide weak evidence that adding immigration to a Solow migration model raises the convergence coefficient. Barro and Sala-i-Martin (2004, p.486) write: "The evidence here is not definitive but suggests that migration plays only a minor role in the convergence story." In equations that omit the population variable but are otherwise identical to those in the columns of table 2 , the coefficient on the lagged dependent variable is (standard errors in parentheses): -0.137 (0.012) for the fixed effects model (compared to -0.110 , from column 2 in table 2); -0.349 (0.010) for the first difference model (compared to -0.326, from column 3 in table 2); -0.841 (0.097) for the Difference GMM (compared to -0.698 in table 2); and -0.756 (0.032) for the System GMM (compared to -0.722 in table 2).

The results presented in table 2 suggest that while general population growth has a negative impact on income per capita in an average county, Hispanic population growth has a positive impact. ${ }^{10}$ However, table 3 shows that Hispanic population growth has a positive impact on per capita income only in those counties that had been losing population in the 1970s and 1980s and only in small towns and rural counties (counties not in an MSA). When the economic growth regression is re-run using data only from counties that had been losing population, the estimated impact of Hispanic population growth on per capita income growth is positive and statistically significant in all specifications. On the other hand, in the estimates of the economic growth equations that use data only from counties whose populations were growing in the 1970s and 1980s, the results from most specifications indicate that Hispanic population growth has negative impacts on per capita income. Table 3 also presents the estimates of the growth regressions separately for counties in large metropolitan areas (PSMAs), smaller MSAs, and non-MSAs (small towns and rural areas). Only in the small towns and rural areas (non-MSAs) is the estimated impact of Hispanic population growth consistently positive and significant. In large and small metropolitan areas Hispanic population growth has a negative or insignificant estimated impact on economic growth in all but one specification.

Table 4 reinforces the point that Hispanic population growth has a positive impact on per capita income growth only in small towns and rural areas that had been losing population in the

counties, but omit the population variables, then the absolute value of the coefficient on the lagged dependent variable is consistently larger than the absolute value on the lagged dependent variable when the population variables are included. These results are available upon request.

${ }^{10}$ Because we do not weight the data by a county's population, the regression results do not represent the impact of population growth on the average person in the United States, but rather on an average county. 
1970s and 1980s; for this group of counties the coefficient on the Hispanic population variable is always positive and significant, no matter the econometric technique used to estimate the economic growth equation. Using our preferred 2SLS-IV estimates, a $1 \%$ increase in the Hispanic population in these counties leads to a $0.12 \%$ to $0.17 \%$ increase in the growth rate of per capita real income. Hispanic population growth also has a (smaller) positive impact in small towns and rural areas where the population grew in the 1970s and 1980s. On the other hand, in the estimates using data from large cities and smaller MSAs, the estimated impact of Hispanic population growth on per capita income is either negative or statistically insignificant (except for the system GMM estimate, which failed some specification tests and which we therefore view with some skepticism).

The results of the estimated per capita income growth regressions clearly indicate that Hispanic immigrant and population growth has had a positive impact on real income per capita in America's small towns and rural areas in the last 25 years. On the other hand, there is no clear evidence that the influx of Hispanic immigrants has had a similar positive impact on the economies of counties in small or large metropolitan areas.

\section{Robustness checks}

In this section we describe several checks of the robustness of our main findings. We do not include tables of these results because they are very similar to those reported already, but they are available upon request.

One possibility is that what we have found is evidence that the influx of Hispanics has induced an increase in government transfer payments into the county. In order to test this possibility, we re-estimated the economic growth regressions after subtracting transfers from the measure of income (so that income measured only non-transfer income). The results of this specification test indicate that transfer payments are not driving our results. In these alternative growth regressions a larger Hispanic population in a county causes increases in the per capita income growth rate, but only in counties not in MSAs. As above, the positive impact of Hispanic population growth is larger in those counties that had been losing population in the 1970s and 1980s. The magnitudes of the estimated effects are similar to those reported above and in the tables. 
In the main analysis, we used first difference regression and the log of the Hispanic and non-Hispanic population to capture the impact of changes in these populations on economic growth. As a specification test, we also re-estimated the economic growth regressions using the rates of growth of the Hispanic and non-Hispanic populations as independent variables, as is done in much of the economic growth literature (for example, Barro and Sala-i-Martin, 1994 and 2005). As another specification test, we also re-estimated the economic growth regressions using the log of total population and the proportion of the population that is Hispanic as two independent variables, as is common in the migration literature (especially the literature on the impact of immigration on wages as in, for example, Card, 2007). The results of the regressions using both of these alternative measures of the Hispanic population in a county are consistent with the results presented in this paper. That is, a higher growth rate in the Hispanic population (or a higher proportion of the population that is Hispanic) in a county causes increases in the per capita income growth rate, but only in counties not in MSAs. As above, both alternative specifications indicate that the positive impact of Hispanic population growth is larger in those counties that had been losing population in the 1970s and 1980s. The magnitudes of the estimated effects are similar to those reported earlier.

As our final specification test, we re-estimated the instrumental variable equations excluding the lagged Hispanic population in the first stage regressions (leaving only heating and cooling days as instruments). When we did this, the signs and significance levels of the coefficients on the population variables in the structural equations were the same as those reported in the table.

In summary, our results do not appear to be sensitive to the econometric technique used to estimate the growth regressions, to the functional form of the population variables, to the specific measurement of the per capita income variable, nor to the specific set of instrumental variables used.

\section{Summary}

In the 1990s, rural and small towns in the United States, which had been losing population, became the destinations for an increasing number of Hispanic immigrants and their families. In this paper, we have focused on the question of whether Hispanic immigration into American small towns and rural areas has benefited those communities whose populations had 
been declining in the 1970 s and 1980 s by reviving their economic growth. The answer to this question is yes; a growing Hispanic population has a causal positive effect on real per capita income in counties not in metropolitan statistical areas. These same positive effects of a growing Hispanic population are not found for counties in metropolitan statistical areas (either large or small SMSAs). Further, the positive impact of Hispanic immigration on small towns and rural areas is larger for those non-metropolitan areas that had been losing their non-Hispanic population, compared to those that had been gaining population. These results are very robust across several specifications and the econometric technique used to estimate the economic growth regressions.

The reason for the causal connection between Hispanic influx and faster growth may be one or more of several possibilities. Perhaps Hispanic immigrants and their children can revitalize small towns because they make the population younger; possibly the immigrants have human capital, entrepreneurial talent or a willingness to work long and hard, and at jobs natives will not take, that can provide a shot in the arm to the local economy. While our analysis cannot identify the precise mechanism by which Hispanic immigration contributes to small town growth, we do establish the existence of this relationship in the data. As such, we can reject the suggestion that the Hispanic immigrants are a drain on already struggling small town and rural economies.

Economic growth is only one potential impact of a growing Hispanic population on small towns and rural areas. Extensions to this paper should seek to understand how the immigrants have affected the public fiscal situation, the structure of local economies, or the cost of living. Future research on these issues in combination with the findings of this paper are necessary if we are to answer completely the question posed in the title, "Are Hispanic Immigrant Families Reviving the Economies of America's Small Towns?”. 


\section{BIBLIOGRAPHY}

Arellano, Manuel, and Stephen R. Bond. 1991. "Some Tests of Specification for Panel Data: Monte Carlo Evidence and an Application to Employment Equations." Review of Economics and Statistics, 58(2): 277-297.

Barro, Robert J., and Xavier Sala-i-Martin. 2004. Economic Growth: Second Edition. Cambridge: MIT Press.

Barro, Robert J., and Xavier Sala-i-Martin. 1995. Economic Growth. Cambridge: MIT Press.

Becker, Gary. 1993. Human Capital: A Theoretical and Empirical Analysis, with Special Reference to Education: Third Edition. Chicago: University of Chicago Press.

Blundell, Richard W., and Stephen R. Bond. 1998. "GMM Estimation with Persistent Panel Data: An Application to Production Functions." Econometric Reviews, 19(3): 321-340.

Bond, Stephen., Anke Hoeffler, and Jonathan Temple. 2001. "GMM Estimation of Empirical Growth Models.” Center for Economic Policy Research Discussion Paper 3048.

Borjas, George. 1987. "Self-Selection and the Earnings of Immigrants." American Economic Review, 77(4): 531-53.

Borjas, George. "The Economics of Immigration." Journal of Economic Literature 32 (1994): 1667-717.

Borjas, George, Stephen Bronars, and Stephen Trejo. 1992. "Self-selection and Internal Migration in the United States." Journal of Urban Economics, 32(2): 159-185.

Brezis, Elise, and Paul Krugman. 1996. "Immigration, Investment and Real Wages.” Journal of Population Economics, 9(1): 83-93.

Card, David. 2007. "How Immigration Affects U.S. Cities." Centre for Research and Analysis of Migration Discussion Paper 11-07.

Card, David, and Ethan Lewis. 2007. "The Diffusion of Mexican Immigrants During the 1990s: Explanations and Impacts." In Mexican Immigration, ed. George Borjas, 193-228. Chicago: University of Chicago Press.

Caselli, Francesco, Gerardo Esquivel, and Fernando Lefort. 1996. "Reopening the Convergence Debate: A New Look at Cross-Country Growth Empirics.” Journal of Economic Growth, 1(3): 363-389.

Chiswick, Barry. 1999. “Are Immigrants Favorably Self-Selected?” American Economic Review, 89(2): 181-185. 
Chiswick, Barry, and Paul Miller. 2008. "Why is the Payoff to Schooling Smaller for Immigrants?” Labour Economics, 15(6): 1317-1340.

Dolado, Juan, Alessandra Goria, and Andrea Ichino. 1994. "Immigration, Human Capital and Growth in the Host Country: Evidence from Pooled Country Data." Journal of Population Economics, 7(1): 193-215.

El Nasser, Haya. 2008. "Counties Feel the Impact of Hispanic Immigration; Newer Arrivals Counter Communities' Shrinking Younger Populations." USA Today. June 30, 1.

Etzo, Ivan. 2008a. "Internal Immigration: a Review of the Literature." Munich Personal RePEc Archive Paper No. 8783.

Etzo, Ivan. 2008b. "Internal Migration and Growth in Italy." Munich Personal RePEc Archive Paper No. 8642.

Friedberg, Rachel M., and Jennifer Hunt. 1995. "The Impact of Immigration on Host Country Wages, Employment, and Growth." Journal of Economic Perspectives, 9(2): 23-44.

Gezici, Ferhan, and Geoffrey J.D. Hewings. 2004. "Regional Convergence and the Economic Performance of Peripheral Areas in Turkey." Review of Urban and Regional Development Studies, 16(2): 113-132

Grey, Mark, and Anne Woodrick. 2005. 'Latinos Have Revitalized Our Community: Mexican Migration and Anglo Responses in Marshalltown, Iowa." In New Destinations: Mexican Immigration in the United States, ed. Victor Zuniga and Ruben Hernandez-Leon, 133-154. New York: Russell Sage Foundation.

Hall, Robert E. and Jones, Charles I. 1999. "Why Some Countries Produce So Much More Output Per Worker Than Others?” Quarterly Journal of Economics, 114(1): 83-116.

Hanson, Gordon. 2002. "The Economic Consequences of the International Migration of Labor." National Bureau of Economic Research Working Paper 14490.

Hoeffler, Anke. 2002. "The Augmented Solow Model and the African Growth Debate." Oxford Bulletin of Economics and Statistics, 64(2): 135-158.

Jensen, Leif. 1989. The New Immigration: Implications for Poverty and Public Assistance Utilization. New York: Greenwood Press.

Johnson, Kenneth, and Daniel Lichter. 2008. "Natural Increase: A New Source of Growth in Emerging Hispanic Destinations in the United States." Population and Development Review, 34(2): 327-346. 
Kirdar, Murat, and Sirin Saracoglu. 2007. "Regional Convergence and the Causal Impact off Migration on Regional Growth Rates.” Middle East Technical University Department of Economics, Ankara, Turkey.

Mankiw, Gregory, David Romer, and David Weil. 1992. "A Contribution to the Empirics of Economic Growth.” The Quarterly Journal of Economics, 107(2): 407-437.

Osterbye, Stein and Olle Westerlund. 2007. "Is Migration Important for Regional Convergence? Comparative Evidence for Norwegian and Swedish Counties, 1980-2000." Regional Studies, 41(7): 901-915.

Ottaviano, Gianmarco I. P., and Giovanni Peri. 2006. "Rethinking the Effects of Immigration on Wages.” National Bureau of Economic Research Working Paper 12497.

Parente, Stephen, and Edward Prescott. 1994. "Barriers to Technology Adoption and Development." The Journal of Political Economy, 102(2): 298-321.

Parente, Stephen, and Rui Zhao. 2006. "Slow Development and Special Interests." International Economic Review, 47(3): 991-1011.

Peeters, Ludo. 2008. "Selective In-migration and Income Convergence and Divergence Across Belgian Municipalities.” Regional Studies, 42(7): 905-921.

Peri, Giovanni. 2007. “Immigrants' Complementarities and Native Wages: Evidence from California." National Bureau of Economic Research Working Paper 12956.

Perssons, Joakim. 1997. “Convergence Across the Swedish Counties, 1911-1993.” European Economic Review, 41(9): 1835-1852.

Poot, Jaques. 2008. "Demographic Change and Regional Competitiveness: The Effects of Immigration and Ageing." International Journal of Foresight and Innovation Policy, 4(1/2): 129-145.

Saiz, Albert. 2003. "Room in the Kitchen for the Melting Pot: Immigration and Rental Prices." Review of Economics and Statistics, 85 (3): 502-521.

Saiz, Albert. 2007. "Immigration and Housing Rents in American Cities." Journal of Urban Economics, 61(2): 345-371.

Shioji, Etsuro. 2001. "Composition Effect of Migration and Regional Growth in Japan." Journal of the Japanese and International Economies, 15(1): 29-49.

Soto, Aristides, and Raimundo Torche. 2004. "Spatial Inequality, Migration, and Economic Growth in Chile." Cuadernos de Economia, 41(124): 401-424. 
Zuniga, Victor, and Ruben Hernandez-Leon. 2005. New Destinations: Mexican Immigration in the United States. New York: Russell Sage Foundation. 


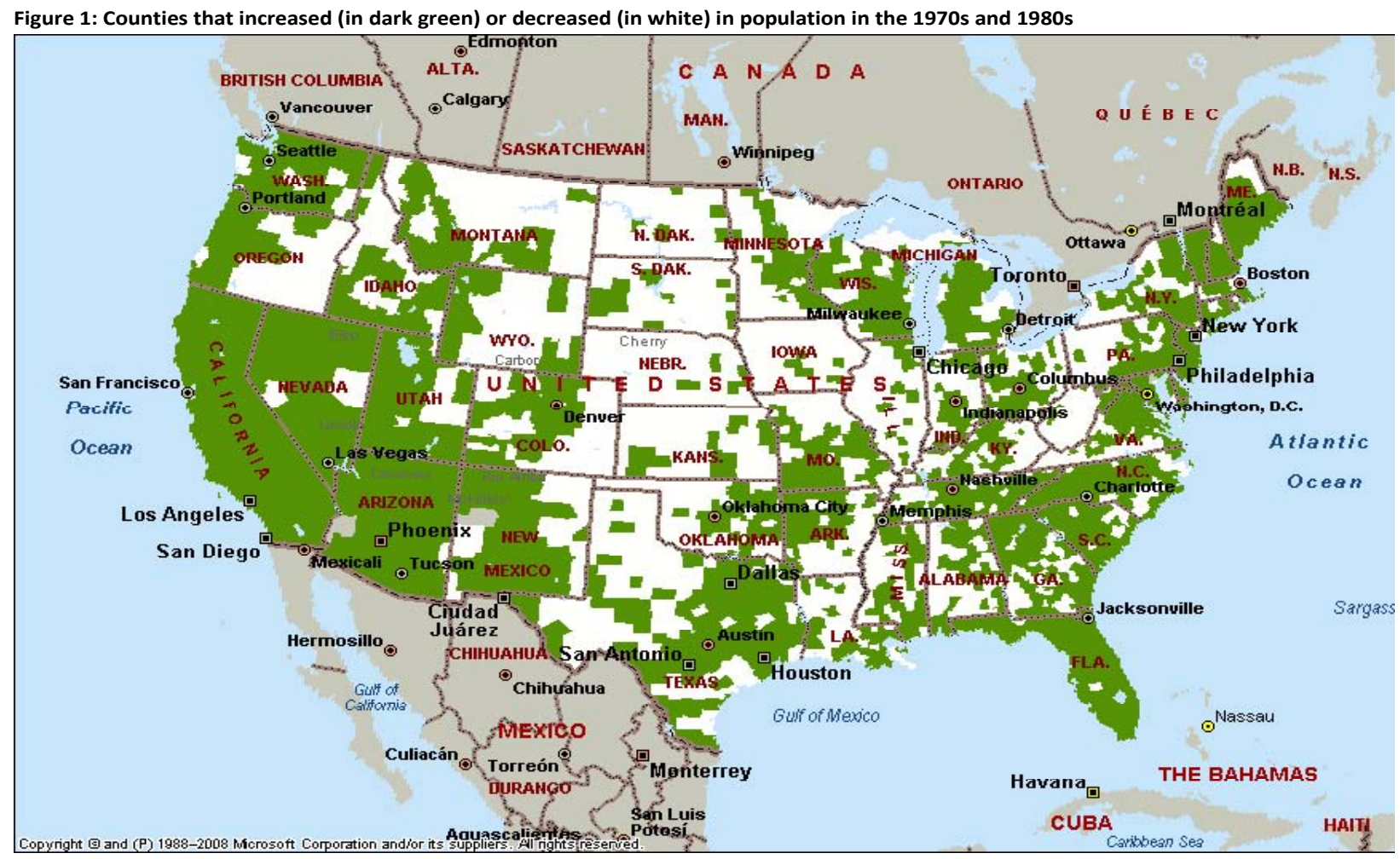

Figure 2: Counties where the Hispanic population grew and the Non-Hispanic population fell from 1990-2005 (in light green), counties where both Hispanic and non-Hispanic population grew (dark green) and counties where both Hispanic and non-Hispanic population fell (white)

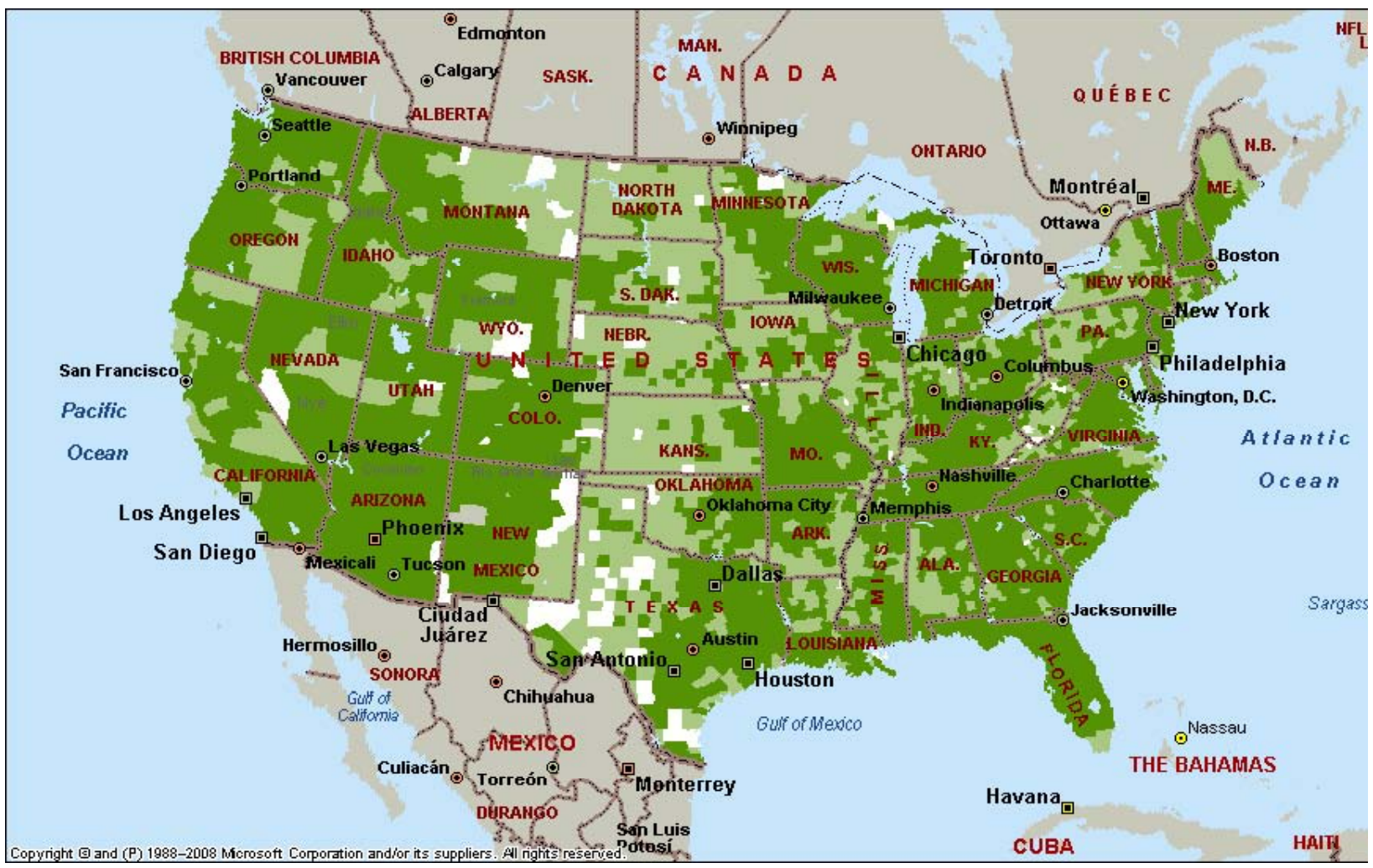


Table 1: Relative Contribution of Hispanic and Non-Hispanic Population to Population Growth from 1990 to 2005, calculated separately for counties where population declined or grew in the 1970 s and 1980 s

$\begin{array}{lll}\text { Total Population } & \text { Contribution of } & \begin{array}{l}\text { Contribution of } \\ \text { Non-Hispanics }\end{array}\end{array}$

\section{All Counties}

with declining population in

1970 s or 1980 s ( 1479

counties)

$2.2 \%$

$3.6 \%$

$-1.5 \%$

with growing population in

1970s or 1980s (1622

counties)

$26.6 \%$

$10.8 \%$

$15.7 \%$

Large Metropolitan Areas (PSMSAs)

with declining population in

1970 s or 1980 s (36 counties)

$3.0 \%$

$5.4 \%$

$-2.4 \%$

with growing population in

1970 s or 1980 s (111 counties)

$24.5 \%$

$15.4 \%$

$9.2 \%$

Smaller Metropolitan Areas (small SMSAs)

with declining population in

1970 s or 1980 s (113 counties)

$2.4 \%$

$2.8 \%$

$-0.4 \%$

with growing population in

1970 s or 1980 s (439 counties)

$29.0 \%$

$9.8 \%$

$19.2 \%$

\section{Non-metropolitan Areas (Non-MSAs)}

with declining population in

1970s or 1980s (1308

counties)

$0.7 \%$

$2.0 \%$

$-1.3 \%$

with growing population in

1970s or 1980s (1072

counties)

$24.0 \%$

$5.8 \%$

$18.1 \%$

Source: Authors' calculations using data from the State and County data book.

Notes: Using the decomposition of population growth rates described in Card (2007, page 5). 
Table 2: Per Capita Income Growth Regressions, using data from all U.S. counties

\begin{tabular}{|c|c|c|c|c|c|c|c|c|c|c|c|c|c|c|c|}
\hline \multirow{2}{*}{ Variable } & \multicolumn{3}{|c|}{ Specification } & & & & & & & & & & & & \\
\hline & \multicolumn{3}{|c|}{$\begin{array}{l}\text { OLS with county } \\
\text { fixed effects }\end{array}$} & \multicolumn{3}{|c|}{$\begin{array}{l}\text { 2SLS-IV with county } \\
\text { fixed effects }\end{array}$} & \multicolumn{3}{|c|}{$\begin{array}{l}\text { 2SLS-IV (first } \\
\text { difference) }\end{array}$} & \multicolumn{3}{|c|}{ Difference GMM } & \multicolumn{3}{|c|}{ System GMM } \\
\hline Dependent Variable: & $\log$ of $\operatorname{Re}$ & al PerC & Capi & ita Income & & & & & & & & & & & \\
\hline $\begin{array}{l}\text { Lagged Dependent } \\
\text { Variable }\end{array}$ & -0.116 & $(0.012)$ & $* * *$ & -0.11 & $(0.015)$ & $* * *$ & -0.326 & $(0.013)$ & $* * *$ & -0.698 & (0.099) & *** & -0.722 & $(0.035)$ & ) $* * *$ \\
\hline $\begin{array}{l}\text { Log of Hispanic } \\
\text { Population }\end{array}$ & 0.005 & $(0.002)$ & ** & 0.074 & $(0.016)$ & $* * *$ & 0.069 & $(0.014)$ & $* * *$ & 0.052 & $(0.012)$ & $* * *$ & 0.014 & $(0.006)$ & $* *$ \\
\hline $\begin{array}{l}\text { Log of Non-Hispanic } \\
\text { Population }\end{array}$ & -0.015 & $(0.010)$ & & -0.438 & $(0.083)$ & $* * *$ & -0.596 & $(0.130)$ & $* * *$ & -0.698 & $(0.010)$ & *** & 0.109 & $(0.014)$ & $* * *$ \\
\hline \% High School & 0.009 & $(0.000)$ & *** & 0.008 & $(0.000)$ & $* * *$ & 0.009 & $(0.001)$ & $* * *$ & 0.01 & $(0.008)$ & *** & 0.017 & $(0.001)$ & *** \\
\hline$\%$ College & 0.012 & $(0.001)$ & $* * *$ & 0.019 & $(0.002)$ & $* * *$ & 0.019 & $(0.002)$ & $* * *$ & 0.024 & $(0.002)$ & $* * *$ & 0.008 & $(0.001)$ & $* * *$ \\
\hline$\%$ Age $0-5$ & 0.027 & $(0.002)$ & *** & 0.037 & $(0.004)$ & $* * *$ & 0.028 & $(0.004)$ & $* * *$ & 0.027 & $(0.005)$ & *** & 0.007 & $(0.005)$ & \\
\hline \% Age 18-64 & 0.006 & $(0.001)$ & $* * *$ & 0.015 & $(0.002)$ & $* * *$ & 0.009 & $(0.002)$ & $* * *$ & 0.004 & $(0.002)$ & $* *$ & -0.001 & $(0.002)$ & \\
\hline$\%$ Age 65 and up & 0.006 & $(0.001)$ & *** & & $(0.002)$ & & -0.001 & $(0.003)$ & & -0.006 & $(0.003)$ & ** & 0.016 & $(0.002)$ & $* * *$ \\
\hline Time Dummies & YES & & & YES & & & YES & & & YES & & & YES & & \\
\hline $\begin{array}{l}\text { Sargan/Hansen test } \\
\text { (p-value) }\end{array}$ & - & & & 0.643 & & & 1.000 & & & 0.000 & & & 0.000 & & \\
\hline $\begin{array}{l}\text { Hausman test } \\
\text { (p-value) }\end{array}$ & - & & & 0.000 & & & 0.000 & & & 0.000 & & & 0.000 & & \\
\hline $\begin{array}{l}\text { Arellano-Bond } \mathrm{AR}(1) \\
\text { test statistic }\end{array}$ & - & & & - & & & -3.982 & $* * *$ & & 9.187 & $* * *$ & & 4.99 & $* * *$ & \\
\hline
\end{tabular}

Notes: Significant at $10 \%\left({ }^{*}\right)$; significant at $5 \%\left({ }^{* *}\right)$; significant at $1 \%(* * *)$. Standard errors are in parenthesis.

All reported standard errors and test statistics are heteroskedasticity-consistent. 
Table 3: Coefficients on the variables that measure the impact of hispanic and non-hispanic population on economic growth in per capita income

\begin{tabular}{|c|c|c|c|c|c|c|c|c|c|c|c|c|c|c|c|}
\hline & \multicolumn{3}{|c|}{ Specification } & & & & & & & & & & & & \\
\hline & \multicolumn{3}{|c|}{$\begin{array}{l}\text { OLS with county } \\
\text { fixed effects }\end{array}$} & \multicolumn{3}{|c|}{$\begin{array}{l}\text { 2SLS-IV with county } \\
\text { fixed effects }\end{array}$} & \multicolumn{3}{|c|}{$\begin{array}{l}\text { 2SLS-IV (first } \\
\text { difference) }\end{array}$} & \multicolumn{3}{|c|}{ Difference GMM } & \multicolumn{3}{|c|}{ System GMM } \\
\hline \multicolumn{4}{|c|}{ Sample: Counties with: } & & & & & & & & & & & & \\
\hline \multicolumn{16}{|c|}{ Population Loss in the 1970s and 1980s } \\
\hline Hispanic & 0.012 & $(0.004)$ & $* * *$ & 0.151 & $(0.041)$ & $* * *$ & 0.158 & $(0.041)$ & *** & 0.041 & $(0.019)$ & $* * *$ & 0.041 & $(0.007)$ & $* * *$ \\
\hline Non-hispanic & -0.130 & $(0.029)$ & $* * *$ & -0.413 & $(0.629)$ & & 0.499 & $(0.707)$ & & -1.028 & $(0.198)$ & & 0.059 & $(0.016)$ & $* * *$ \\
\hline \multicolumn{16}{|c|}{ Population Gain in the 1970s and 1980s } \\
\hline Hispanic & -0.003 & $(0.003)$ & & -0.036 & $(0.016)$ & $* *$ & -0.026 & $(0.014)$ & * & 0.044 & $(0.019)$ & $* *$ & -0.038 & $(0.019)$ & $* * *$ \\
\hline Non-hispanic & 0.017 & $(0.011)$ & & -0.067 & $(0.068)$ & * & 0.050 & $(0.091)$ & & -0.488 & $(0.128)$ & $* * *$ & 0.183 & $(0.394)$ & $* * *$ \\
\hline \multicolumn{16}{|l|}{ PSMA } \\
\hline Hispanic & -0.012 & $(0.017)$ & & 0.474 & $(0.489)$ & & $-2.896^{\prime}$ & (20.8) & & 0.288 & $(0.114)$ & ** & -0.028 & $(0.014)$ & ** \\
\hline Non-hispanic & -0.022 & $(0.031)$ & & -0.626 & $(0.741)$ & & 5.711 & $(50.7)$ & & -0.259 & $(0.203)$ & & 0.025 & $(0.026)$ & \\
\hline \multicolumn{16}{|l|}{ Small MSA } \\
\hline Hispanic & -0.012 & $(0.005)$ & $* *$ & -0.081 & $(0.030)$ & $* * *$ & -0.091 & $(0.033)$ & $* * *$ & -0.016 & $(0.022)$ & & -0.060 & $(0.011)$ & *** \\
\hline Non-hispanic & 0.089 & $(0.015)$ & *** & 0.107 & $(0.063)$ & * & 0.197 & $(0.087)$ & ** & 0.176 & $(0.060)$ & $* * *$ & 0.104 & $(0.024)$ & *** \\
\hline \multicolumn{16}{|l|}{ Non-MSA } \\
\hline Hispanic & 0.009 & $(0.003)$ & $* * *$ & 0.058 & $(0.016)$ & $* * *$ & 0.062 & $(0.013)$ & $* * *$ & 0.061 & $(0.015)$ & $* * *$ & 0.030 & $(0.005)$ & $* * *$ \\
\hline Non-hispanic & -0.041 & $(0.013)$ & $* * *$ & -0.536 & $(0.091)$ & $* * *$ & -0.690 & $(0.014)$ & $* * *$ & 0.887 & $(0.110)$ & $* * *$ & 0.017 & $(0.017)$ & \\
\hline
\end{tabular}

Notes: Significant at $10 \%\left({ }^{*}\right)$; significant at $5 \%\left({ }^{* *}\right)$; significant at $1 \%(* * *)$. Standard errors are in parenthesis. All reported standard errors and test statistics are heteroskedasticity-consistent. 
Table 4: Coefficients on the variables that measure the impact of hispanic and non-hispanic population on economic growth in per capita income

\begin{tabular}{|c|c|c|c|c|c|c|c|c|c|c|c|c|c|c|}
\hline & \multicolumn{2}{|c|}{ Specification } & & & & & & & & & & & & \\
\hline & \multicolumn{2}{|c|}{$\begin{array}{l}\text { OLS with county } \\
\text { fixed effects }\end{array}$} & \multicolumn{3}{|c|}{$\begin{array}{l}\text { 2SLS-IV with county } \\
\text { fixed effects }\end{array}$} & \multicolumn{3}{|c|}{$\begin{array}{l}\text { 2SLS-IV (first } \\
\text { difference) }\end{array}$} & \multicolumn{3}{|c|}{ Difference GMM } & \multicolumn{3}{|c|}{ System GMM } \\
\hline \multicolumn{15}{|c|}{ Sample: Counties with: } \\
\hline \multicolumn{15}{|c|}{ PMSA-Population Loss in the 1970s and 1980s } \\
\hline Hispanic & 0.016 & $(0.036)$ & 0.250 & (0.399) & & -0.025 & $(0.212)$ & & 0.106 & $(0.102)$ & & -0.017 & $(0.020)$ & \\
\hline Non-hispanic & 0.352 & $(0.143)^{* *}$ & 0.388 & $(0.849)$ & & 0.625 & $(1.004)$ & & -0.766 & (0.911) & & 0.000 & $(0.057)$ & \\
\hline \multicolumn{15}{|c|}{ PMSA--Population Gain in the 1970 s and 1980s } \\
\hline Hispanic & -0.032 & $(0.019) *$ & 0.358 & $(0.434)$ & & -1.153 & $(2.488)$ & & 0.464 & (0.143) & )*** & -0.029 & $(0.015)$ & * \\
\hline Non-hispanic & -0.048 & (0.033) & -0.357 & $(0.630)$ & & 2.492 & $(4.370)$ & & -0.411 & (0.198) & ** & 0.042 & $(0.030)$ & \\
\hline \multicolumn{15}{|c|}{ Small MSA-Population Loss in the 1970 s and 1980 s } \\
\hline Hispanic & -0.020 & $(0.010) *$ & \begin{tabular}{|l}
0.387 \\
\end{tabular} & (0.966) & & -0.148 & $(0.160)$ & & -0.063 & (0.053) & & -0.051 & $(0.028)$ & * \\
\hline Non-hispanic & 0.303 & $(0.068)^{* * *}$ & -2.991 & (8.322) & & -0.036 & $(1.436)$ & & -0.293 & $(0.384)$ & & 0.167 & $(0.048)$ & *** \\
\hline \multicolumn{15}{|c|}{ Small MSA--Population Gain in the 1970s and 1980s } \\
\hline Hispanic & \begin{tabular}{|l}
-0.011 \\
\end{tabular} & $(0.005)^{* *}$ & \begin{tabular}{|l}
-0.084 \\
\end{tabular} & $(0.028)$ * & *** & -0.087 & $(0.030)$ & ) *** & 0.002 & (0.024) & & -0.065 & $(0.011)$ & *** \\
\hline Non-hispanic & 0.060 & $(0.019))^{* * *}$ & 0.087 & $(0.077)$ & & 0.204 & $(0.102)$ & )** & 0.154 & $(0.074)$ & )** & 0.107 & $(0.025)$ & *** \\
\hline \multicolumn{15}{|c|}{ Non-MSA-Population Loss in the 1970s and 1980s } \\
\hline Hispanic & 0.014 & $(0.004)^{* * *}$ & 0.171 & $(0.030)$ & *** & 0.123 & $(0.019)$ & ) *** & 0.118 & (0.056) & )** & 0.054 & $(0.013)$ & *** \\
\hline Non-hispanic & -0.148 & $(0.031) * *$ & 0.600 & $(0.351)$ & $*$ & 0.345 & $(0.302)$ & & -1.964 & $(0.385)$ & ) $* * *$ & -0.004 & $(0.034)$ & \\
\hline \multicolumn{15}{|c|}{ Non-MSA-Population Gain in the 1970s and 1980s } \\
\hline Hispanic & 0.002 & $(0.003)$ & 0.024 & (0.019) & & 0.037 & $(0.016)$ & ) ** & 0.060 & (0.017) & )*** & 0.021 & $(0.006)$ & *** \\
\hline Non-hispanic & -0.028 & $(0.015) *$ & -0.413 & $(0.116) *$ & *** & -0.346 & $(0.164)$ & )** & -1.035 & (0.170) & )*** & 0.099 & $(0.018)$ & *** \\
\hline
\end{tabular}

Notes: Significant at $10 \%\left({ }^{*}\right)$; significant at $5 \%\left({ }^{* *}\right)$; significant at $1 \%\left({ }^{* * *}\right)$. Standard errors are in parenthesis. All reported standard errors and test statistics are heteroskedasticity-consistent. 
Table A1: Descriptive Statistics

\begin{tabular}{lccccc}
\multicolumn{1}{c}{ Mean } & Std Dev & Min & Max & $\mathrm{N}$ \\
All Counties & \multicolumn{7}{c}{} \\
$\begin{array}{l}\text { Economic Growth (log difference in real per capita incomes) } \\
1970-1980\end{array}$ & 0.141 & 0.143 & -1.213 & 1.031 & 3101 \\
$1980-1990$ & 0.184 & 0.147 & -0.681 & 1.413 & 3101 \\
$1990-2000$ & 0.133 & 0.106 & -0.787 & 0.773 & 3101 \\
$2000-2005$ & 0.050 & 0.095 & -2.631 & 0.604 & 3101
\end{tabular}

For the sample used in the economic growth regressions (1980, 1990 and 2000)

$\begin{array}{lrrrrr}\text { Hispanic Population } & 7448.1 & 7267.5 & 0.0 & 1257529.0 & 9303 \\ \text { Non-Hispanic Population } & 73652.2 & 210354.3 & 58.2 & 5522214.0 & 9303 \\ \text { \% with high school education } & 68.8 & 12.9 & 25.1 & 97.0 & 9303 \\ \text { \% with college education } & 13.8 & 6.9 & 2.8 & 60.5 & 9303 \\ \text { \% 0-5 years old } & 7.1 & 1.3 & 0.0 & 18.0 & 9303 \\ \text { \% 18 years and older } & 72.7 & 4.0 & 0.0 & 100.0 & 9303 \\ \text { \% 65 years and older } & 14.3 & 4.3 & 0.0 & 34.7 & 9303 \\ \text { cold degree days } & 1315.7 & 854.2 & 6.0 & 4461.0 & 9228 \\ \text { heating degree days } & 4864.9 & 2131.9 & 85.0 & 10343.0 & 9228\end{array}$

\section{Non-MSAs}

Economic Growth (log difference in real per capita incomes) for the following periods:

$\begin{array}{llllll}1970-1980 & 0.164 & 0.156 & -1.213 & 1.031 & 2380 \\ 1980-1990 & 0.185 & 0.160 & -0.681 & 1.413 & 2380 \\ 1990-2000 & 0.125 & 0.113 & -0.787 & 0.773 & 2380 \\ 2000-2005 & 0.059 & 0.084 & -1.354 & 0.604 & 2380\end{array}$

For the sample used in the economic growth regressions (1980, 1990 and 2000)

$\begin{array}{lrrrrr}\text { Hispanic Population } & 1130.6 & 4155.6 & 0.0 & 102837.3 & 7140 \\ \text { Non-Hispanic Population } & 23299.2 & 21277.5 & 58.2 & 220331.0 & 7140 \\ \text { \% with high school education } & 67.1 & 13.1 & 25.1 & 96.3 & 7140 \\ \text { \% with college education } & 12.3 & 5.4 & 3.1 & 60.5 & 7140 \\ \text { \% 0-5 years old } & 7.0 & 1.4 & 0.0 & 18.0 & 7140 \\ \text { \% 18 years and older } & 72.6 & 4.1 & 0.0 & 100.0 & 7140 \\ \text { \% 65 years and older } & 15.1 & 4.2 & 0.0 & 34.7 & 7140 \\ \text { cold degree days } & 1319.1 & 840.6 & 6.0 & 4461.0 & 7140 \\ \text { heating degree days } & 4958.4 & 2161.3 & 173.0 & 10343.0 & 7140\end{array}$

